\title{
INTERNALLY COOLED MONOLITHIC SILICON NITRIDE AEROSPACE COMPONENTS
}

\author{
Jonathan E. Best and James D. Cawley \\ Materials Science and Engineering \\ Case Western Reserve University \\ Cleveland, Ohio 44106
}

\author{
Ramakrishna T. Bhatt* and Dennis S. Fox** \\ *Army Research Laboratory Vehicle Tech. Dir. \\ **NASA Glenn Research Center \\ Cleveland, Ohio 44135
}

A set of rapid prototyping (RP) processes have been combined with gelcasting to make ceramic aerospace components that contain internal cooling geometry. A mold and core combination is made using a MM6Pro (Sanders Prototyping, Inc.) and SLA-250/40 (3Dsystems, Inc.). The MM6Pro produces cores from ProtoBuild ${ }^{\mathrm{TM}}$ wax that are dissolved in room temperature ethanol following gelcasting. The SLA-250/40 yields epoxy/acrylate reusable molds. Parts produced by this method include two types of specimens containing a high density of thin long cooling channels, thin-walled cylinders and plates, as well as a model hollow airfoil shape that can be used for burner rig evaluation of coatings. Both uncoated and mullite-coated hollow airfoils has been tested in a Mach 0.3 burner rig with cooling air demonstrating internal cooling and comfirming the effectiveness of mullite coatings.

\section{INTRODUCTION}

The efficiency of a gas turbine engine is increased by raising the turbine inlet temperature and the maximum temperature is ultimately limited by material properties. In order to approach service near $90 \%$ of their melting point, superalloy blades and vanes have become elegantly engineered ${ }^{1}$. In part this is microstructural, for example, the progression from equiaxed to directionally solidified to single crystal and the gamma gamma-prime strengthening. But of equal importance is the development of coring technologies that permit internal cooling and the application of environmentally resistant coatings. The former allows the surface temperature of the component to kept to a maximum that is significantly below the ambient whereas the latter mitigates the effects of oxidation and other corrosion processes as well as providing a thermal barrier.

Much of the work on producing ceramic materials has focused of the development of material properties such as resistance to thermal shock and oxidation, high temperature strength and stiffness, and creep resistance. And the results have been singularly successful. In particular, both commercial and research grades silicon nitrides (usually alloys containing rare earth oxides in combination with aluminosilicates) are available which can tolerate sudden quenches in excess of $1000^{\circ} \mathrm{C}$, have strengths greater than $800 \mathrm{MPa}$, and which tolerate service operating temperatures up to $1300^{\circ} \mathrm{C}$. In-situ reinforced silicon nitride formulations have been developed with fracture toughnesses in excess of $8 \mathrm{MPa} \sqrt{\mathrm{m}}$.

The combination of such properties are immediately suggestive of application in gas turbine (and rocket) applications ${ }^{2}$. Furthermore, the effectiveness of internal cooling has been demonstrated by Tsuchiya et $\mathrm{al}^{3}$ who have shown that the it is reasonable to for the surface temperature of silicon nitride components in a $1500^{\circ} \mathrm{C}$ environment to be kept below $1300^{\circ} \mathrm{C}$ through the use of internal air cooling, which require modest flows.

Engineering the surface is suggested by work that has been done demonstrating the use of plasma-sprayed mullite to produce thermal and environmental barrier coatings on silicon carbide and silicon nitride ${ }^{4}$.

The work reported herein represents an effort to develop a process strategy to prototype silicon nitride parts capable of internal cooling that is robust and easy to 
implement. Conceptually, the process is quite straightforward: molds and cores are produced by two different commercial RP processes and assembled; a gelcasting slurry is prepared and forced into the cavity under low pressure; after gelling, the part is liberated through a combination of dissolution to remove the cores and diassembly to remove the reusable molds. The resultant wet part is dried and fired via conventional means. Details of the process are given elsewhere ${ }^{5}$.

Gelcasting is a process developed at Oak Ridge National Laboratory ${ }^{6}$ and it is particularly amenable to use with soft tooling, such as that produced by polymer-based RP processes because only very low pressures are employed. In fact, Jamalabad et al. suggested the use of gelcasting in fugitive molds sometime ago ${ }^{7}$. The approach taken in this work differs in that a combination of RP methods is used, the design of the molding system is different, and that a process for setting the gel, immersion is a poly(ethylene glycol) (PEG), is used incorporated.

The particular implementation of gelcasting used in this work uses water-soluble organic materials. Two monomers are employed: methacrylamide (MAM) which polymerizes as a linear chain and N,N'-methylenebisacrylamide (MBAM) which is a crosslinker. Just prior to casting an initiator, $N, N, N^{\prime}, N^{\prime}-$ tetramethylethylenediamine (TEMED), and a catalyst, ammonium peroxydisulfate (APS), are mixed into the slurry to commence the gelation process.

Standard stereolithography was used to produce reusable molds. A SLA250/40 was used to build epoxy/acrylate parts that survived molding and subsequent immersion in ethanol and PEG without noticeable damage or distortion. Dozens of casts were made using the same epoxy/acrylate parts.

The Sanders Prototyping process was used to produce cores and mold lines which were dissolved, after casting, by soaking in room temperature ethanol for several hours. A ModelMaker MM6Pro was used. The Sanders process employs two materials to built a part. The actual part is built out of a "green wax" (ProtoBuild ${ }^{\mathrm{TM}}$ ) and the surrounding supports are built out of a "red wax" (ProtoSupport ${ }^{\mathrm{TM}}$ ). The waxes are melted and each layer of the part is deposited using two separate ink jets to spray droplets. A mechanical grinder levels off each layer to the correct thickness. These process steps continue until the entire part is built.

Upon completion the red supporting wax can be selectively removed by heating to $40-50^{\circ} \mathrm{C}$ in a VS-O bath. Beyond the fact that the green wax can be dissolved with ethanol at room temperature, this method is particularly suited to the production of cores or small characteristic dimension or requiring fine details.

All CAD work was carried out using Rhino3D (Robert McNeel and Associates) a NURBS package that runs on Pentium ${ }^{\mathrm{TM}}$ class PCs.

\section{PROCEDURE}

Three types of parts were built. The first was a reverse-engineered model airfoil shape based on archival superalloy parts left over from the original thermal barrier coating development program at NASA Lewis Research Center (now NASA Glenn Research Laboratory). The part allows internal cooling and was readily coated with plasma sprayed mullite. The other two were demonstration parts to permit the a critical evaluation of the possibility for using thin cooling channels of long length within the walls of thin-walled plates and cylindrical sections.

In initial experiments, molds were entirely epoxy/acrylate and a mold release was used to effect separation of the gelled part from the mold. Although often successful, distortion due to demolding stresses was enough of a nuisance that soluble mold linings were developed and used with great success. Mold linings were made by the exact same process as the cores and so were simultaneously removed. The net result is that the space filled by 
the slurry was entirely bounded by surfaces made up of the Protobuild material. This was true for all of the parts discussed.

Figure 1 shows the CAD representation of the molding system used to make the thinwalled internally cooled hollow cylinder. Similar mold systems are used for other components. In practice, the joints of the assembled mold were sealed with a soft patching wax (Kindt-Collins) and held together with teflon tape as needed. After the casting has gelled, the entire mold is immersed in ethanol to dissolve the wax components of the molds. Leachable paths are designed such that all the wax parts are connected to the external surface. The wax linings and cores dissolve away in a few hours. The part is then submerged in PEG for drying. As the gating structure would restrict drying shrinkage creating undesirable stresses within the part, it is trimmed from the part prior to drying. After the part is dried, typical ceramic firing procedures are employed. The process steps are illustrated in Fig. 2 using a different mold/core set to illustrate each.

\section{FABRICATED PARTS}

The results of the molding process as well represented by the results shown in Fig. 3 for the cylinder. The cast part contains some flashing that must be manually removed, but the overall shape and size is accurate and the high density of small diameter holes produced by the cores are excellent. The pathway of the cooling holes is visible in the fired piece because of the locally thin walls. Very similar results were obtained with the flat plate.

The simulated airfoil specimen is documented in Figs. 4 and 5. Figure 4 illustrates the results of the reverse engineering process and Fig. 5 shows the resultant silicon nitride version, which was an excellent geometrical match for the original casting.

Mach 0.3 jet fuel burner rig testing was conducted on superalloy, uncoated silicon nitride and mullite-coated silicon nitride specimens. A typical test condition is illustrated in the photograph appearing in Fig. 6. Quantitatively results indicate that cooling air produced the expected comparable reductions in surface temperature, up to $130^{\circ} \mathrm{C}$ for flowrates of approximately $1.5 \mathrm{lit} / \mathrm{s}$.

\section{CONCLUSIONS}

The fabrication of internally cooled monolithic silicon nitride aerospace components has been demonstrated. Gelcasting coupled with rapid prototyping technology allows for the production of these components which range from thin-walled shapes with cooling channels to simpler hollow shapes. The internal geometry of these parts is made possible by wax cores produced by the Sanders Prototyping process, which can be dissolved from wet gelcast parts with ethanol. This technique brings the same flexibility of shape forming associated with metal casting to the realm of ceramics processing. A hollow silicon nitride airfoil produced with this process has been tested with cooling air in a Mach 0.3 burner rig. Cooling air reduced the surface temperature up to $130^{\circ} \mathrm{C}$ below the uncooled condition of $1185^{\circ} \mathrm{C}$.

\section{ACKNOWLEDGEMENTS}

Z. Liu, CWRU, was of enormous help in general ceramic processing and rapid prototyping. R. Babuder, CWRU/NASA, was similarly invaluable in his help with binder burnout and firing. Mike Cuy, NASA, assisted with the burner rig testing. The work was funded under NASA/CWRU Cooperative Agreement on Ceramic Processing Grant \# NAS3-404. 


\section{REFERENCES}

1. C. T. Sims, “A History of Superalloys for Superalloy Metallurgists," pg. 399 in Superalloys 1984, edited by M. Gell, C. S. Kortovich, R. H. Bricknell, W. B. Kent, and J. F. Radavich, AIME, 1984.

2. Pollinger, J.P., Progress in fabrication of silicon nitride structural components for turbomachinery applications. ASME Paper 96-GT-347.

3. Tsuchiya, T., Furuse, Y., Yoshino, S., Chikami, R., Tsukagoshi, K., Mori, M., Development of air-cooled ceramic nozzles for a power generating gas turbine. ASME Paper 95-GT-105.

4. K. N. Lee and R. A. Miller, "Development and Environmental Durability of Mullite and Mullite/YSZ Dual Layer Coatings for $\mathrm{SiC}$ and $\mathrm{Si}_{3} \mathrm{~N}_{4}$ Ceramics," Surface and Coatings Technology, 86-87 [1-3] 142-8 (1996).

5. J. E. Best, J. D. Cawley, R. Bhatt, and D. Fox, "Fabrication and Testing of Internally Cooled Monolithic Silicon Nitride Aerospace Components, J. Am. Ceram. Soc., submitted.

6. O. O. Omatete, M. A. Janney, S. D. Nunn, "Gelcasting: from Laboratory Development toward Industrial Production. Journal of the European Ceramic Society 17 (1997) 407413.

7. Jamalabad, V.R., Whalen, P.J., Pollinger, J., "Gelcast molding with rapid prototyped fugitive molds,", pp. 71-78 in Proceedings of the Solid Freeform Fabrication Symposium, ed. D.L. Bourell, J.J. Beaman, H.L. Marcus, R. H. Crawford, J. W. Barlow. The University of Texas at Austin, Austin, Texas, 1996.

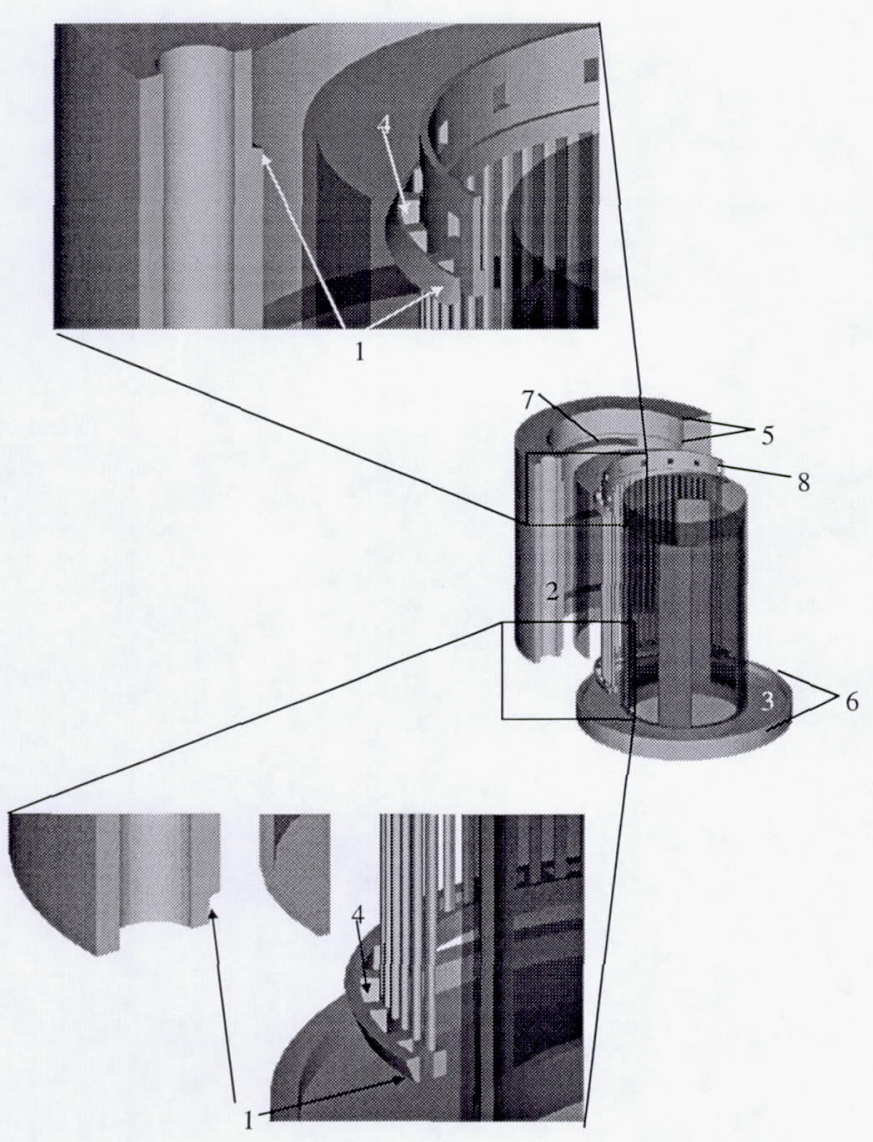

Figure 4.11 shows the CAD rendition of the assembly of the thin-walled internally cooled cylinder mold system. The individual parts can be seen in the center overview from right to left: inner gating, inner lining, core half, outer lining half, outer gating half. The design feature are highlighted numerically: 1)registration features, 2)slurry casting tube, 3)bottom filling tray, 4)flow path slats in core, 5)overflow space, 6)gate removal is accomplished by cutting along this plane, 7)uppermost of three slots for dissolution of outer lining, 8)leachable ethanol path for core dissolution (square cutouts are obsolete flow paths). 


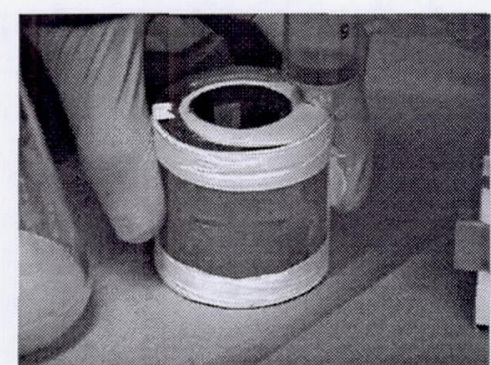

a)



b)

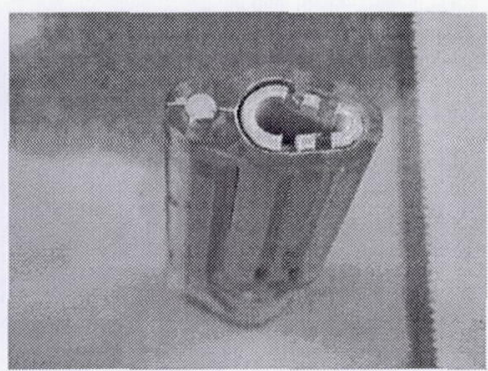

c)

Figure 2 shows the processing steps of the soluble core gelcasting process: a) filling the mold, b) dissolving ProtoBuild mold components in ethanol, and c) the final green part separated from, but still within the epoxy/acrylate mold.

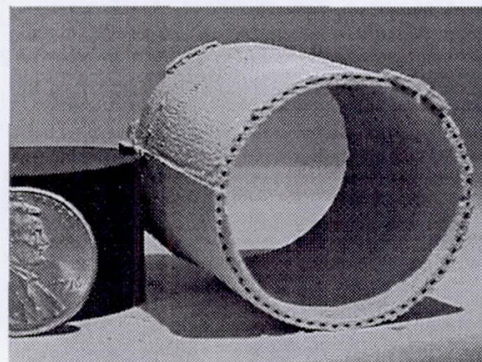

a)

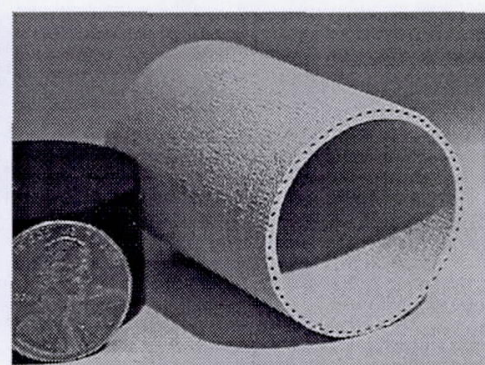

b)

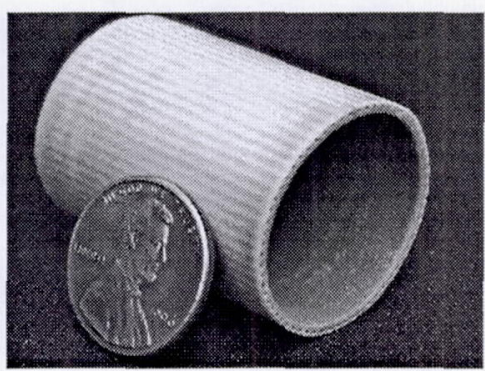

c)

Figure 3 shows various views of the thin-walled cooled cylinder: a) untrimmed green state, b) trimmed green state, and c) fired component. Diameter of coin is $19.05 \mathrm{~mm}$.

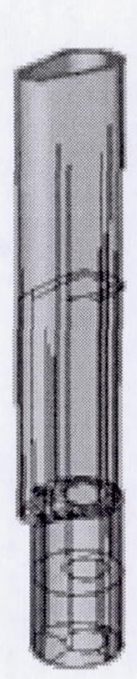

a)

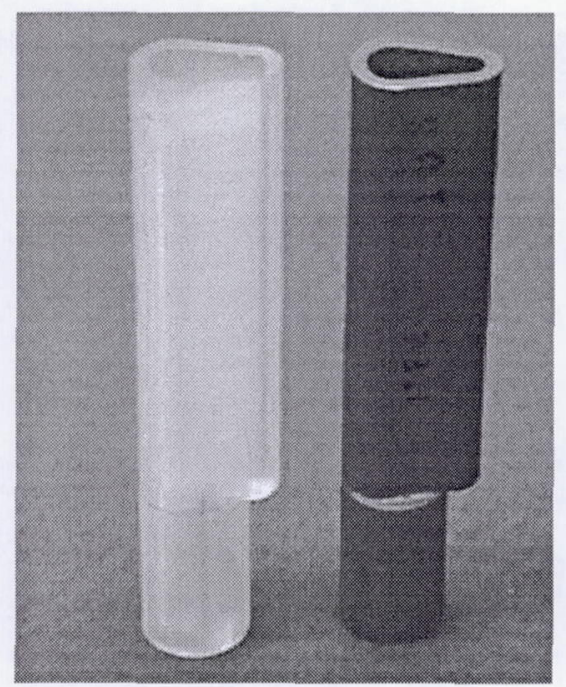

c)

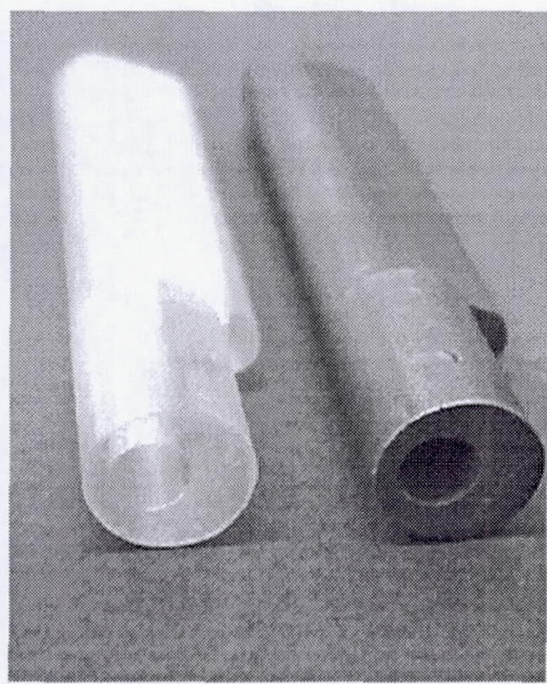

b)

Figure 4 Reverse engineering of a internally cooled model airfoil test specimen. a) Deduced CAD file from measurements on original casting. b) and c) Two views of the original casting and a stereolithography model made for verification purposes. 

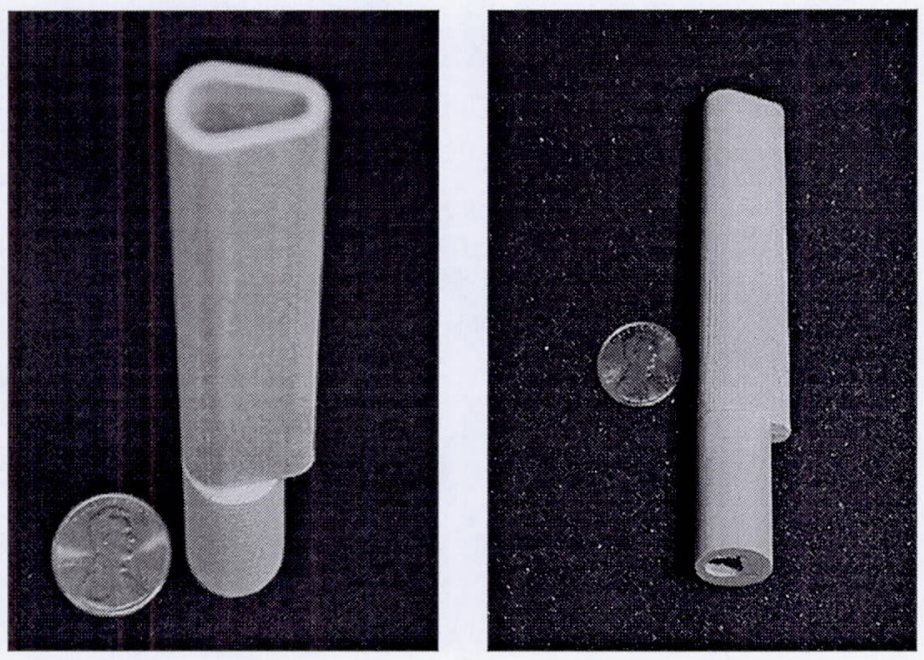

Figure 5 Two views of the green hollow simulated airfoil. Diameter of coin is $19.05 \mathrm{~mm}$.

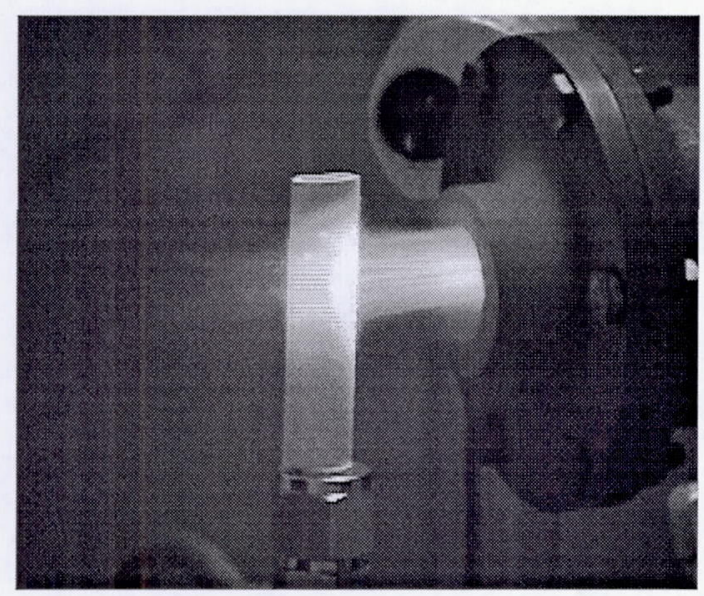

Figure 6 Silicon nitride airfoil in Mach 0.3 jet fuel burner flame with. 3 lit/s of cooling air. Superalloy casting and mullite-coated airfoils also were tested. 